\title{
Uso da arquitetura pedagógica Projeto de Aprendizagem como suporte à prática docente em aulas síncronas
}

\author{
Ana Beatriz Michels ${ }^{1}$, Ricardo Daniell Prestes Jacaúna ${ }^{2}$, Crediné Silva de \\ Menezes $^{3}$ \\ ${ }^{1,2} 2$ e Programa de Pós-Graduação em Informática na Educação - Universidade Federal \\ do Rio Grande do Sul (UFRGS) \\ Porto Alegre - RS - Brazil \\ \{ana.michels@ufrgs.br, riccardojacauna@gmail.com, credine@gmail.com\}
}

\begin{abstract}
The use of active methodologies, when planned according to the precepts of a pedagogical architecture structure, provides opportunities for the cooperative construction of knowledge by the students. This paper presents an experience of using the Learning Project pedagogical architecture as a proposal for learning by inquiry. From an explanatory research, of a qualitative nature, the pedagogical architecture is presented as a potential qualification of the teaching practice, being exemplified through a research that sought to answer how to favor collaborative activities in synchronous online classes. The experience made it possible to exercise awareness of the topic worked on.
\end{abstract}

Resumo. $O$ uso de metodologias ativas, quando planejadas segundo os preceitos de uma arquitetura pedagógica, oportuniza a construção cooperativa de conhecimento pelos alunos. O presente artigo apresenta uma experiência de uso da arquitetura pedagógica Projeto de Aprendizagem enquanto proposta de aprendizagem por investigação. A partir de uma pesquisa explicativa, de natureza qualitativa, a arquitetura pedagógica é apresentada enquanto potencial qualificação da prática docente, sendo exemplificada através de uma questão de investigação que buscou responder como favorecer atividades colaborativas em aulas síncronas online. A experiência possibilitou o exercício de tomada de consciência sobre o tema trabalhado.

\section{Introdução}

Os avanços da educação mediada pelas tecnologias, numa perspectiva da educação 5.0 [Silva 2021; Rasmuin, Widiani 2020], vem desafiando os diversos atores envolvidos no processo, em especial os professores. Esse novo contexto educacional, com foco no aprendizado ativo, colaborativo e cooperativo, onde o aluno assume o papel de protagonista, ressignifica o papel do professor, a quem agora cabe os papéis de mediador e problematizador do conhecimento.

No processo de aprendizagem colaborativa e cooperativa, centrado na atuação dos alunos, o conhecimento não parte nem do aluno e nem do objeto de estudo, mas na interação indissociável entre eles. Se por um lado a colaboração se resume na união das ações isoladas de cada aluno, em prol de um objetivo comum, a cooperação envolve muita reciprocidade e complementaridade nas ações dos alunos [Piaget, 1973]. Em ambas, a interação entre os alunos estimula o desenvolvimento de competências como pensamento 
científico, crítico e criativo; cultura digital; argumentação; autoconhecimento e autocuidado; empatia e colaboração, conforme relata Garofalo (2019).

A aprendizagem ativa [Valente, Almeida, Geraldini 2017; Ghilay, Ghilay 2015], que pode ser explorada com o uso de metodologias colaborativas e cooperativas, permite a realização de atividades em grupo em torno de um problema real, a valorização do conhecimento prévio dos alunos, o compartilhamento dos saberes, a empatia e a liberdade de expressão. Essas características são premissas da proposta de arquiteturas pedagógicas [Menezes, Castro-Jr e Aragón 2020; Carvalho, Nevado e Menezes 2007], definida como estruturas de aprendizagem que "englobam ideias epistemológicas relacionais, pedagogias abertas, tecnologias digitais e novos referenciais de tempo e espaço como condições estruturantes para as aprendizagens individuais e construções coletivas" [Aragón 2016]. Por esse viés, as arquiteturas pedagógicas desafiam os professores na busca e identificação de necessidades, de recursos didáticos e de ferramentas web que possam desencadear um processo de aprendizagem ativa nos seus alunos. Nesse processo, os alunos interagem entre pares e são orientados pelo professor por meio de intervenções que estimulam a construção da autonomia, da cooperação, da investigação e o desenvolvimento da habilidade de metareflexão.

O cenário atual, ocasionado pelo isolamento social, fruto da pandemia do Covid19, ao mesmo tempo que desafia os professores a se reinventarem e inovarem em suas práticas pedagógicas, abre possibilidades para uma melhoria na sua qualidade profissional em prol de uma educação digital em rede [Moreira, Schlemmer 2021]. Dentre as possibilidades e desafios existentes, um deles refere-se ao fortalecimento da aprendizagem cooperativa nos modelos de ensino adotados por diferentes instituições de ensino superior, em especial o Ensino Remoto Emergencial - ERE. Estudos na área de interação social mostram que "[...] um senso de propósito compartilhado é essencial para uma interação online de sucesso" [Cunningham 2013].

Um modelo de aprendizagem cooperativa conectado com as tecnologias digitais é uma forma de romper com o modelo tradicional de ensino - seja ele presencial e/ou online - se conectando com as demandas da sociedade e dos alunos. E esse modelo, a partir de atividades em grupo possibilitadas por várias tecnologias, amplia o envolvimento e a autonomia dos alunos criando espaços virtuais interativos que conduzem a aprendizagem [Cavinato 2021].

Com base nesse contexto, o artigo relata a experiência dos autores numa disciplina de doutorado do Programa de Pós-Graduação em Informática na Educação da UFRGS, que envolveu um estudo sobre uma metodologia de aprendizagem ativa que oportuniza a construção de conhecimento com base numa questão de investigação levantada pelos próprios alunos.

\section{Percurso Metodológico}

Esta pesquisa, de natureza explicativa e qualitativa [Yin 2016], relata uma experiência de uso da arquitetura pedagógica Projeto de Aprendizagem - PA [Fagundes, Sato, Maçada 2006], enquanto potencial qualificação da prática docente e proposta de estratégia pedagógica de incentivo à aprendizagem por investigação. O percurso metodológico está dividido em 11 etapas conectadas com a sequência didática da arquitetura pedagógica PA, que busca "[...] apoiar os aprendizes na construção do conhecimento sobre um tema especialmente significativo a cada um" [Castro, Menezes 2011]. 
O uso da arquitetura pedagógica PA foi uma das atividades experienciadas na disciplina Aprendizagem Cooperativa em Contextos Digitais, dentro do Programa de PósGraduação em Informática na Educação (PPGIE) da UFRGS. A disciplina foi realizada no período de agosto a novembro de 2020, sendo que essa atividade ocorreu ao longo de oito semanas, conforme etapas apresentadas no Quadro 1. Enquanto autores do artigo e alunos e professor da disciplina, a experiência de uso da arquitetura pedagógica com foco na investigação de uma questão de interesse apresenta uma visão dupla de aluno e professor, visto que os autores são professores-formadores em áreas específicas.

Quadro 1. Etapas de desenvolvimento da arquitetura pedagógica Projeto de Aprendizagem

\begin{tabular}{|l|l|}
\hline \multicolumn{1}{|c|}{ Período } & \multicolumn{1}{c|}{ Etapas } \\
\hline \multirow{2}{*}{ Semana 1} & 1. Formulação coletiva de perguntas \\
\cline { 2 - 3 } & 2. Formação dos grupos \\
\hline \multirow{2}{*}{ Semana 2 } & 3. Elaboração do site \\
\cline { 2 - 3 } & 4. Pesquisa - Levantamento do conhecimento prévio \\
\hline \multirow{2}{*}{ Semana 3 } & 5. Pesquisa - Mapa conceitual inicial \\
\cline { 2 - 3 } & 6. Pesquisa - Elaboração do plano de ação \\
\hline \multirow{2}{*}{ Semanas 4 a 6 } & 7. Pesquisa - Desenvolvimento da pesquisa \\
\cline { 2 - 3 } & 8. Pesquisa - Relatório de conclusão da investigação \\
\hline Semana 7 & 9. Socialização dos resultados \\
\hline \multirow{2}{*}{ Semana 8 } & 10. Visitação e avaliação das pesquisas de outros três grupos \\
\cline { 2 - 2 } & 11. Avaliação da aprendizagem \\
\hline
\end{tabular}

A primeira etapa do percurso metodológico refere-se à formulação coletiva de perguntas. Todos os alunos da disciplina foram convidados a elaborar dez perguntas, via fórum geral do Moodle, com as quais gostariam de despender tempo para descobrir como respondê-las. As perguntas foram organizadas numa planilha, juntando aquelas repetidas ou similares.

$\mathrm{Na}$ etapa dois do percurso cada aluno acessou a planilha das perguntas e elencou as três de maior interesse em investigar. Os grupos foram formados com base nos interesses em comum, tendo em torno de três integrantes cada grupo. Esse artigo apresenta os resultados de um dos grupos que escolheu como questão de investigação “Como favorecer atividades colaborativas em aulas síncronas online?".

Após a formação dos grupos, deu-se início às etapas de elaboração da pesquisa, buscando responder à questão de investigação. Na etapa três do percurso, cada grupo criou um site ${ }^{1}$ para realizar a construção do projeto de aprendizagem, envolvendo cada momento da pesquisa. A plataforma utilizada foi o Pbworks $^{2}$, que é um ambiente para apoio ao trabalho colaborativo.

A etapa quatro envolveu o levantamento do conhecimento prévio de cada um dos integrantes do grupo, divididos em certezas provisórias e dúvidas temporárias. As certezas envolvem o levantamento do que já conhecem, sendo que as "certezas provisórias" são aquelas que são apenas crenças dos sujeitos, para as quais ainda não possuem uma fundamentação teórica, vistas como um conhecimento de senso comum. E

\footnotetext{
${ }^{1}$ Site do Projeto: https://www.accd20201grupo01.pbworks.com/.

2 https://www.pbworks.com/.
} 
as dúvidas referem-se aquilo que ainda não se sabe e que é necessário para a elaboração de respostas para a questão de investigação, por isso são chamadas de "dúvidas temporárias", podendo ser uma subdivisão da questão principal em questões menores. E já nesse momento inicial há uma oportunidade de aprendizagem, tendo um confronto do que cada integrante da equipe sabe com o que os outros sabem, gerando um debate e troca de informações entre eles [Castro, Menezes 2011].

Todo esse conhecimento prévio foi organizado na etapa cinco do percurso, através da elaboração de um mapa conceitual inicial. Dentre as ferramentas online de construção de mapas conceituais, a escolhida pelo grupo foi o Cmap Cloud ${ }^{3}$.

A busca de respostas para a questão de investigação envolve a validação das certezas e o esclarecimento das dúvidas, buscando transformar informações em conhecimentos. A etapa seis do percurso metodológico inicia-se com a elaboração do plano de ação, onde são elencadas potenciais fontes de consulta como artigos, vídeos, instrumentos de pesquisa e responsáveis por cada momento. Em relação à questão de investigação apresentada nesse artigo, os alunos-autores buscaram artigos publicados em periódicos nacionais e internacionais e construíram um questionário online, via Google Forms, tendo como público-alvo dois perfis de professores: $(i)$ aquele que já ministrava aulas síncronas online no modelo híbrido (aulas presenciais e a distância) e/ou totalmente a distância antes da pandemia ocasionada pelo Covid-19 e (ii) aquele que está ministrando aulas síncronas online no período de pandemia (ERE).

A amostra relacionada aos respondentes do questionário envolveu 34 professores vinculados às instituições de ensino onde os autores trabalham, sendo 28 do Ensino Superior, 3 do Ensino Médio e 3 do Ensino Fundamental. Destes, 94\% se enquadram no perfil ( $i i)$, que são professores que não ministravam aulas síncronas online antes da pandemia do Covid-19, e apenas $6 \%$ no perfil $(i)$, professores que já tinham experiência com aulas síncronas online antes da pandemia. Além disso, $60 \%$ deles se consideram usuários com conhecimento intermediário em relação ao uso de tecnologias digitais na Educação, 23\% com conhecimento inicial e 17\% com conhecimento avançado.

Após a coleta de dados, a etapa sete do percurso envolveu o registro dos dados no site e a elaboração das conclusões do grupo sobre os itens de pesquisa (relatórios parciais). Cada relatório constituiu-se em textos hipermidiáticos que integraram artigos, imagens, vídeos e questionário online.

A etapa oito do percurso refere-se à construção do relatório de conclusão da investigação, com base em todos os relatórios parciais. Para evidenciar as aprendizagens, foi elaborado um novo mapa conceitual, que foi construído a partir do mapa inicial com o acréscimo de novos conceitos e relações descobertos no processo de investigação, bem como pela eliminação de conceitos e relações que não persistiram após a validação das certezas provisórias.

$\mathrm{Na}$ etapa nove do percurso, que foi realizada na sétima semana de atividades, todos os grupos socializaram seus resultados com os demais alunos da disciplina, através da construção de um vídeo, de até vinte minutos, abordando o processo das etapas da arquitetura pedagógica PA, com foco nas descobertas geradas acerca da questão de investigação.

\footnotetext{
3 https://cmapcloud.ihmc.us/.
} 
A etapa dez envolveu a visitação e avaliação dos projetos de aprendizagem construídos por outros três grupos. Cada aluno, de forma individual, acessou o site de outros grupos e avaliou toda a estrutura de construção do projeto de aprendizagem. No final, foi apresentado um relatório de visita envolvendo observações sobre $(i)$ aspectos metodológicos, (ii) resultados obtidos com a pesquisa, (iii) trabalho em equipe, (iv) organização do espaço virtual, (v) vídeo de apresentação do trabalho, (vi) uso de tecnologias, (vii) questões que gostaria que fossem respondidas pelo grupo com respeito aos aspectos que o visitante considera relevante e (viii) outras observações que considera relevante.

A última etapa do percurso metodológico refere-se à avaliação da aprendizagem, do grupo e também de forma individual. A avaliação envolveu os registros nos sites ao longo do projeto de aprendizagem e também as reflexões geradas ao longo das semanas de realização da atividade. Nesse sentido, a etapa avaliativa é um instrumento de apoio à metareflexão, contribuindo com novas aprendizagens. O processo avaliativo, enquanto relatório, abordou o olhar de cada aluno para as atividades realizadas ao longo do semestre. As reflexões contextualizaram (i) síntese acerca de cada tópico abordado na disciplina; (ii) descrição, de forma comparativa e detalhada, sobre a compreensão de cada tópico abordado no início e término da disciplina; (iii) alcance do grau de aprofundamento - insatisfatório, baixo, bom, mediano, bom, excelente e (iv) evidências do envolvimento no estudo sobre cada conceito.

\section{Resultados e Discussões}

A busca à questão de investigação como favorecer atividades colaborativas em aulas síncronas online, com a arquitetura pedagógica PA, envolveu os interesses e conhecimentos prévios dos alunos e autores do artigo. Esse tema de interesse foi escolhido por ser muito atemporal e, ao mesmo tempo, de extrema importância para o momento atual que a humanidade está vivenciando devido a pandemia ocasionada pelo Covid-19, em destaque a Educação.

O processo de investigação, ao longo da jornada das oito semanas de atividades, teve momentos de divergências e convergências entre os desenvolvedores do PA. A aprendizagem cooperativa foi proporcionada, em especial, pelas discussões síncronas online, momentos aos quais os alunos puderam expor seus conhecimentos prévios, organizando-os enquanto grupo e definindo uma proposta de plano de ação. Esses momentos reforçam a importância da própria questão de investigação, onde atividades colaborativas, sejam elas online ou presenciais, auxiliam no processo de aprendizagem dos alunos.

O momento de maior divergência, e que a própria sequência didática da arquitetura pedagógica estimula, foi a etapa inicial do levantamento do conhecimento prévio dos membros da equipe. Essa é a única etapa que inicia com um olhar individual, onde cada aluno precisa analisar suas vivências e aprendizagens para elencar suas certezas provisórias e dúvidas temporárias acerca do tema de interesse. Inicialmente foram compartilhadas 25 sentenças relacionadas às certezas provisórias e 8 com dúvidas temporárias, somando a visão de todos os integrantes da equipe. Após uma primeira discussão interativa online, onde foram analisadas as sentenças para entender o que cada aluno quis afirmar e questionar, as mesmas foram reorganizadas. Algumas foram excluídas, pois eram bastante amplas e fugiam da questão principal, e outras foram 
agrupadas por estarem conectadas e/ou serem sinônimas. Nesse momento, a visão inicial de divergência, que nessa estrutura de aprendizagem se define muito mais como uma ampliação de ideias do que como confronto de ideias entre os pares, deu espaço para um momento de convergência.

Ao final de dois momentos de discussão síncrona online entre os alunos, sendo que o primeiro foi somente entre os alunos e o segundo mediado pelo professor da disciplina e coautor do artigo, os conhecimentos prévios foram agrupados em 11 certezas provisórias e 3 dúvidas temporárias. As sentenças foram organizadas em três grandes categorias/olhares que oportunizam - ou não - o favorecimento de atividades colaborativas nos momentos síncronos online, que foi a base da questão investigativa: $(i)$ olhar do professor para sua prática docente e estratégias de aprendizagem; (ii) olhar do professor para o papel do aluno e seu envolvimento nas aulas síncronas online e (iii) olhar e entendimento do professor sobre as ferramentas tecnológicas.

Dando sequência à dinâmica da arquitetura pedagógica, a proposta não estava mais centralizada apenas na questão investigativa que deu início ao projeto, e sim na busca de um entendimento - teórico e empírico - acerca das certezas provisórias e dúvidas temporárias. Nesse sentido, a equipe trabalhou, de forma colaborativa, no levantamento do referencial teórico e na escolha do instrumento de pesquisa, buscando ter uma amostra para apresentar enquanto resultado empírico. A equipe organizou uma agenda semanal de entregas individuais que eram validadas tanto nas reuniões síncronas online quanto via grupo de whatsapp, que foi a ferramenta escolhida para validações mais pontuais e urgentes.

Como o foco da questão de investigação escolhida pela equipe refere-se ao olhar do professor sobre o favorecimento de atividades colaborativas em aulas síncronas online, o questionário online foi o método escolhido que mais se aproxima das respostas a todas as certezas provisórias. $\mathrm{O}$ questionário envolveu afirmações relacionadas ao conhecimento prévio levantado na etapa inicial da arquitetura pedagógica, nas quais os professores respondentes da pesquisa tinham que se posicionar, numa escala de concordância, utilizando-se 5 pontos, sendo 1 discordo plenamente e 5 concordo plenamente.

\subsection{Olhar do professor para sua prática docente e estratégias de aprendizagem}

O propósito de uma aula síncrona online é promover múltiplas possibilidades de interação, favorecendo o encorajamento de sentimentos de empatia e interações pessoais, conforme afirma Dotta et al (2018). No questionário online, três afirmações estão relacionadas com a abordagem utilizada pelos professores nas aulas síncronas online, sendo que a Tabela 1 mostra o olhar dos professores acerca delas. Os dados mostram que mais de $60 \%$ dos respondentes procuram realizar atividades colaborativas nas suas aulas síncronas online. Por outro lado, apenas $12 \%$ deles discordam de que o foco das aulas síncronas online são para transmitir conteúdo.

Dando sequência, algumas afirmações do questionário envolveram um olhar mais aprofundado da estrutura e planejamento de uma aula, sendo que $95 \%$ dos sujeitos afirmaram que as atividades realizadas nas aulas síncronas online devem ter um propósito, tanto de objetivo quanto de escolha e uso das ferramentas tecnológicas. 
Tabela 1. Foco da estrutura das aulas síncronas online

\begin{tabular}{|l|c|c|c|c|c|}
\hline \multicolumn{1}{|c|}{ Afirmações } & \multicolumn{4}{c|}{ Posicionamentos } \\
\cline { 2 - 5 } & $\mathbf{1}$ & $\mathbf{2}$ & $\mathbf{3}$ & $\mathbf{4}$ & $\mathbf{5}$ \\
\hline $\begin{array}{l}\text { Procuro realizar atividades colaborativas com/entre os alunos } \\
\text { nas aulas síncronas online }\end{array}$ & 2 & 3 & 8 & 12 & 9 \\
\hline $\begin{array}{l}\text { O foco das aulas síncronas online são para tirar dúvidas dos } \\
\text { alunos }\end{array}$ & 8 & 7 & 15 & 2 & 2 \\
\hline O foco das aulas síncronas online são para transmitir conteúdo & $23 \%$ & $20 \%$ & $45 \%$ & $6 \%$ & $6 \%$ \\
\hline
\end{tabular}

Outra certeza provisória levantada era que o professor que não realiza(va) atividades colaborativas nas aulas presenciais terá mais dificuldade de realizar nas aulas síncronas online, sendo que apenas $8 \%$ dos sujeitos não concordaram. Essas afirmações mostram a importância de que a busca e construção de estratégias pedagógicas são inerentes à abordagem educacional adotada pelo professor. A interação não está fundamentada nas tecnologias, e sim na mente do professor e, consequentemente, no seu modelo educacional. Partindo desse pressuposto, quanto mais aberto for o professor ao uso de tecnologias e metodologias ativas no contexto presencial, maior é a probabilidade dele realizar atividades mais ativas e significativas no contexto online.

Para um olhar da abordagem pedagógica utilizada nas aulas síncronas online, três afirmações envolveram o uso de metodologias ativas. A Tabela 2 apresenta a visão dos professores acerca das três afirmações, o que mostra que mais de $80 \%$ deles enxergam na aprendizagem ativa uma oportunidade de proporcionar a colaboração nas atividades síncronas online, tendo a proposta da sala de aula invertida como uma excelente estratégia para conciliar momentos práticos e teóricos ao longo da disciplina.

Tabela 2. Abordagem utilizada pelos docentes nas aulas síncronas online

\begin{tabular}{|c|c|c|c|c|c|}
\hline \multirow{2}{*}{ Afirmações } & \multicolumn{5}{|c|}{ Posicionamentos } \\
\hline & 1 & 2 & 3 & 4 & 5 \\
\hline $\begin{array}{l}\text { A duração de uma atividade nas aulas síncronas online deve } \\
\text { permitir interações e iterações em tempo real }\end{array}$ & $\begin{array}{c}1 \\
3 \%\end{array}$ & $\begin{array}{c}2 \\
6 \%\end{array}$ & $\begin{array}{c}5 \\
15 \%\end{array}$ & $\begin{array}{c}8 \\
23 \%\end{array}$ & $\begin{array}{c}18 \\
53 \%\end{array}$ \\
\hline $\begin{array}{l}\text { A proposta de sala de aula invertida pode ser adotada, sendo } \\
\text { disponibilizado o conteúdo e materiais antes da aula síncrona } \\
\text { online }\end{array}$ & $\begin{array}{c}0 \\
0 \%\end{array}$ & $\begin{array}{c}2 \\
6 \%\end{array}$ & $\begin{array}{c}4 \\
11 \%\end{array}$ & $\begin{array}{c}5 \\
15 \%\end{array}$ & $\begin{array}{c}23 \\
68 \%\end{array}$ \\
\hline $\begin{array}{l}\text { É possível usar metodologias ativas para desenvolver atividades } \\
\text { colaborativas nas aulas síncronas online apenas usando a } \\
\text { plataforma de webconferência }\end{array}$ & $\begin{array}{c}1 \\
3 \%\end{array}$ & $\begin{array}{c}4 \\
11 \%\end{array}$ & $\begin{array}{c}6 \\
18 \%\end{array}$ & $\begin{array}{c}9 \\
27 \%\end{array}$ & $\begin{array}{c}14 \\
41 \%\end{array}$ \\
\hline
\end{tabular}

\subsection{Olhar do professor para o papel do aluno e seu envolvimento nas aulas síncronas online}

Em uma turma, o professor é um dos responsáveis pelo favorecimento de atividades colaborativas nas aulas síncronas online. Porém, como as atividades são elaboradas para serem usadas e/ou construídas entre alunos-alunos e professores-alunos, os alunos também são uma peça essencial nesse processo. Nesse sentido, o questionário envolveu duas afirmações relacionadas ao olhar do professor sobre o perfil de seus alunos, como mostra a Tabela 3.

Percebe-se, na Tabela 3, que mais de $85 \%$ dos professores concordam que o perfil do aluno impacta na realização das atividades, sendo que em muitas situações não participam das atividades. Dessa forma, ao mesmo tempo que o professor busca 
estratégias pedagógicas que estimulem a autonomia e a aprendizagem significativa de seus alunos, o fato dos alunos não participarem ativamente nas atividades síncronas online pode gerar um certo desânimo nos professores. E esse desânimo pode gerar duas potenciais ações antagônicas por parte dos professores, sendo uma delas a busca contínua e diversificada de atividades que favoreçam a aprendizagem colaborativa de seus alunos, e num outro extremo um retorno para uma abordagem mais tradicional de ensino, focando muito mais na transmissão de conteúdo, com um papel mais passivo dos alunos.

Tabela 3. Olhar para o perfil dos alunos nas aulas síncronas online

\begin{tabular}{|l|c|c|c|c|c|}
\hline \multicolumn{1}{|c|}{ Afirmações } & \multicolumn{4}{c|}{ Posicionamentos } \\
\cline { 2 - 5 } & $\mathbf{1}$ & $\mathbf{2}$ & $\mathbf{3}$ & $\mathbf{4}$ & $\mathbf{5}$ \\
\hline $\begin{array}{l}\text { O aluno pode estar presente na atividade síncrona online, mas } \\
\text { não "estar síncrono" na atividade }\end{array}$ & 0 & 0 & 4 & 4 & 26 \\
\hline $\begin{array}{l}\text { O perfil dos alunos impactam de forma positiva - ou negativa - } \\
\text { na realização e evolução das atividades colaborativas nas aulas } \\
\text { síncronas online }\end{array}$ & 0 & $0 \%$ & $11 \%$ & $11 \%$ & $78 \%$ \\
\hline
\end{tabular}

\subsection{Olhar e entendimento do professor sobre as ferramentas tecnológicas}

Numa aula síncrona online, independente de se realizar - ou não - uma atividade interativa, as questões técnicas interferem significativamente. $O$ grau de fluência tecnológica que os professores e alunos possuem, a familiaridade existente com a sala virtual e a experiência com recursos tecnológicos influenciarão decisivamente no andamento da aula.

É comum, em primeiras experiências com aulas síncronas online, surgirem dificuldades técnicas - ajustes de áudio e vídeo, problemas com conexão. A fluência tecnológica vai se constituindo aos poucos, sendo que as dificuldades iniciais, que por alguns momentos geram tensão e insatisfação, vão sendo sanadas até o ponto em que a tecnologia se torna um facilitador da aprendizagem, tornando as aulas mais ágeis.

Pelo olhar de uso e entendimento do professor perante as ferramentas tecnológicas, o questionário abordou três sentenças, como mostra a Tabela 4.

Tabela 4. Olhar de uso e entendimento do professor perante as ferramentas tecnológicas

\begin{tabular}{|l|c|c|c|c|c|}
\hline \multicolumn{1}{|c|}{ Afirmações } & \multicolumn{4}{c|}{ Posicionamentos } \\
\cline { 2 - 5 } & $\mathbf{1}$ & $\mathbf{2}$ & $\mathbf{3}$ & $\mathbf{4}$ & $\mathbf{5}$ \\
\hline Enquanto professor, tenho receio de "encher" meus alunos com & 2 & 3 & 13 & 7 & 9 \\
recursos tecnológicos nas aulas síncronas online & $6 \%$ & $9 \%$ & $38 \%$ & $20 \%$ & $27 \%$ \\
\hline $\begin{array}{l}\text { O professor só usará determinada ferramenta tecnológica se } \\
\text { tiver experimentado a ferramenta antes do seu uso }\end{array}$ & 2 & 3 & 4 & 9 & 16 \\
\hline $\begin{array}{l}\text { A usabilidade e acessibilidade das ferramentas tecnológicas } \\
\text { devem ser verificadas previamente }\end{array}$ & 0 & 0 & 2 & 4 & 28 \\
\hline
\end{tabular}

A Tabela 4 mostra que $94 \%$ dos sujeitos concordam que todos os testes técnicos e a conexão das ferramentas tecnológicas com a proposta da atividade precisam ser realizados e analisados previamente. Por outro lado, $25 \%$ dos sujeitos discordam que ele precisa experimentar a ferramenta tecnológica antes de usá-la em aula. O resultado encontrado está coerente com o resultado de outra pesquisa recente que mostrou que, dentre os desafios postos pela pandemia, “[...] a escassez da formação continuada docente é uma realidade muito presente nas IES, com números que somam 44,3\% raras formações ou nenhuma formação" [Silus, Fonseca, Jesus, p. 14, 2020]. 
Tanto em determinadas capacitações docentes quanto na busca individual, os professores procuram conhecer, num nível instrumental, determinadas ferramentas tecnológicas, ampliando seu repertório de recursos. Porém, quase 50\% da amostra têm consciência de que o uso excessivo de ferramentas tecnológicas numa aula síncrona online pode prejudicar o aprendizado de seus alunos.

\subsection{Conectando os três olhares do professor}

Com base nos resultados da amostra apresentada acima e no referencial teórico levantado e analisado pela equipe ao longo das semanas de investigação, foi possível apresentar um relatório final acerca da questão investigada, buscando conectar os três olhares dos professores. Enquanto potenciais resultados, uma atividade colaborativa síncrona online precisa ter uma estrutura intencional, onde o professor planeja - com base na sua abordagem pedagógica - estratégias educacionais, sabendo os objetivos e potenciais trajetórias de aprendizagem de seus alunos, com o intuito de atingir a sua aprendizagem significativa e, consequentemente, a de seus alunos.

O desenvolvimento de estratégias pedagógicas mais flexíveis e adaptáveis a diferentes contextos, com um olhar para o favorecimento de atividades colaborativas síncronas online e seguindo a proposta da arquitetura pedagógica PA, gera uma valorização do conhecimento prévio dos alunos, o compartilhamento de saberes, empatia, liberdade de expressão e atividades em grupo em torno de um problema real. Com base nos três olhares apresentados anteriormente, o professor é desafiado a exercer três papéis conectados com uma educação 5.0: (i) papel pedagógico, mediando a aprendizagem de seus alunos e usando metodologias ativas para possibilitar uma construção do conhecimento; (ii) papel social, criando condições para a interação entre os alunos e (iii) papel técnico, buscando conhecer ferramentas tecnológicas, desenvolvendo competências acerca de requisitos técnicos.

\section{Considerações Finais}

O novo contexto educacional vem desafiando o professor a planejar estratégias pedagógicas com base em metodologias de aprendizagem ativa. Com a realidade ocasionada pela pandemia do Covid-19, o professor precisa pensar num modelo de aprendizagem colaborativa conectado, cada dia mais, com as tecnologias digitais.

A experiência de uso da tecnologia no ambiente educacional que foi vivenciada pelos alunos-autores, através da arquitetura pedagógica Projeto de Aprendizagem proporcionou uma qualificação de suas práticas docentes, oportunizando o desenvolvimento de uma aprendizagem por investigação. Por ser uma estrutura de aprendizagem que engloba, de forma ampla, o propósito de uma determinada atividade, sua metodologia e um suporte tecnológico, é um conceito inovador a ser disseminado aos professores. Dessa forma, os autores corroboram com Fagundes, Sato, Maçada (2006) no que diz respeito às possibilidades e benefícios pedagógicos do uso desta arquitetura pedagógica em diferentes níveis de escolarização.

Num olhar de avaliação da aprendizagem, que envolveram as etapas finais da arquitetura pedagógica apresentadas no Quadro 1, o uso do Projeto de Aprendizagem contribuiu para que os alunos-autores tivessem uma experiência de aplicação de uma metodologia ativa de aprendizagem cooperativa, possibilitando o exercício de tomada de consciência sobre o tema trabalhado. 
O uso de metodologias ativas, quando planejadas segundo os preceitos das Arquiteturas Pedagógicas, oportuniza a construção cooperativa de conhecimento pelos alunos, principalmente pelo fato de estimular uma mediação distribuída. Os professores desafiam seus alunos a serem protagonistas da sua aprendizagem, de forma individual e coletiva. Adicionalmente, as vivências e olhares de cada aluno quando conectados ao coletivo - enquanto equipe - geram novas discussões, novas ideias, novos desafios e, consequentemente, uma aprendizagem mais significativa.

\section{Referências}

ARAGÓN, R. (2016), Interação e mediação no contexto das arquiteturas pedagógicas para a aprendizagem em rede. Revista de educação pública (Cuiabá). Vol. 25, n. 59/1 (maio/ago. 2016), p. 261-275.

CARVALHO, M. J. S.; NEVADO, R. A.; MENEZES, C.S. (2007) "Arquiteturas Pedagógicas para Educação a Distância”. In: NEVADO. R. A.; CARVALHO, M. J. S. e MENEZES, C. S. (Org.). Aprendizagem em Rede na Educação a Distância: Estudos e Recursos para Formação de Professores. Porto Alegre: Ricardo Lenz.

CASTRO, A.; MENEZES, C. (2011) “Aprendizagem colaborativa com suporte computacional". In: Pimentel, M. e Fuks, H. Sistemas Colaborativos. Rio de Janeiro: Campus, p. 978-85.

CAVINATO, A. G. et al. (2021) "Promoting student interaction, engagement, and success in an online environment".

CUNNINGHAM, U. (2014) "Teaching the disembodied: Othering and activity systems in a blended synchronous learning situation". International Review of Research in Open and Distributed Learning, v. 15, n. 6, p. 33-51.

FAGUNDES, L. C.; SATO, L. S.; MAÇADA, D. L. (2006) "Projeto? O que é? Como se faz". Aprendizes do Futuro: as inovações começaram.

GAROFALO, D. (2019) "Como envolver os alunos na aprendizagem colaborativa. In: Nova escola". https://novaescola.org.br/conteudo/16167/como-envolver-os-alunos-na-aprendizagemcolaborativa.

GHILAY, Y.; GHILAY, R. (2015) "TBAL: Technology-based active learning in higher education”. Ghilay, Y. \& Ghilay, p. 10-18, 2015. https://papers.ssrn.com/sol3/papers.cfm?abstract id=3736634.

GONÇALVES, S.; FONSECA, P.; MALÇA, C. (2016) “Inovação no ensino superior”. MOREIRA, J. A.; SCHLEMMER, E. (2020) "Por um novo conceito e paradigma de educação digital onlife". Revista uFG, v. 20. https://www.revistas.ufg.br/revistaufg/article/view/63438.

MENEZES, C; CASTRO JUNIOR, A. N.; ARAGÓN, R. (2020) "Arquiteturas pedagógicas para aprendizagem em rede". https://ieducacao.ceie-br.org/arquiteturaspedagogicas/.

PIAGET, J. (1973) "Estudos Sociológicos”. Rio de Janeiro: Forense. 
RASMUIN, R.; WIDIANI, D. (2020) "Strategy and implementation of character education in era of society 5.0". In: International Conference on Engineering, Technology and Social Science, Malang, Indonesia.

SILUS, A.; FONSECA, A. L. C.; JESUS, D. L. N. (2020) "Desafios do ensino superior brasileiro em tempos de pandemia da COVID-19: repensando a prática docente". Liinc em Revista, v. 16, n. 2, p. e5336-e5336. http://revista.ibict.br/liinc/article/view/5336.

SILVA, E. F. (2021), "Educação 5.0 - o conectivismo, a revolução digital e o ensino a distância. Contribuições para o ensino híbrido". RECIMA21 - Revista Científica Multidisciplinar, $\mathrm{v}$. 2 , n. 4. http://recima21.com.br/index.php/recima21/article/view/197/207.

VALENTE, J. A.; ALMEIDA, M. E. B.; GERALDINI, A. F. S. (2017) "Metodologias ativas: das concepções às práticas em distintos níveis de ensino". Revista Diálogo $\begin{array}{llllll}\text { Educacional, } & \text { v. } & 17, & \text { n. } & 52, & \text { p. }\end{array}$ ttps://www.redalyc.org/pdf/1891/189154955008.pdf.

YIN, R. K. (2016), “Pesquisa qualitativa do início ao fim”, Porto Alegre, RS: Penso. 